\title{
Perancangan Prosedur Berbasis Manajemen Risiko pada Perguruan Tinggi dalam Rangka Migrasi ke ISO 9001:2015
}

\author{
Dwi Kartikasari ${ }^{*}$ \\ a Jurusan Manajemen Bisnis, Politeknik Negeri Batam,dwi@polibatam.ac.id, Indonesia
}

\begin{abstract}
Di era persaingan pendidikan tinggi yang ketat, berbagai strategi dicanangkan oleh manajemen perguruan tinggi bukan hanya sekedar memastikan keberlangsungannya di masa mendatang, namun juga meningkatkan reputasinya di tingkat nasional dan internasional. Salah satu strategi Politeknik Negeri Batam untuk bertumbuh dengan pesat adalah adopsi sistem manajemen mutu ISO 9001. Oleh karena standar ISO 9001:2008 yang saat ini diterapkan sudah tidak lagi berlaku, maka Politeknik Negeri Batam wajib bermigrasi ke ISO 9001:2015. Pada ISO 9001:2015 terdapat perubahan besar utamanya mengenai penerapan manajemen risiko di mana hal ini tidak dibahas dalam ISO 9001:2008. Dengan demikian, penelitian ini bertujuan untuk menjembatani gap antara persyaratan ISO 9001:2008 dengan ISO 9001:2015 melalui proses identifikasi risiko, penilaian risiko, dan rencana aksi untuk setiap risiko yang teridentifikasi pada setiap prosedur. Objek penelitian ini adalah prosedur perencanaan proses belajar mengajar pada jurusan manajemen bisnis. Data primer diperoleh melalui kegiatan focus group discussion dengan pejabat struktural jurusan Manajemen Bisnis. Data sekunder diperoleh dari bagian Penjaminan Mutu dan sumber daring lain yang valid. Data dianalisis menggunakan risk assessment form. Hasil penelitian ini berupa rancangan prosedur perencanaan proses belajar mengajar yang telah memenuhi persyaratan ISO 9001:2015 dan sesuai kebutuhan organisasi serta telah mengantisipasi risiko yang telah teridentifikasi. Manfaat penelitian ini adalah perguruan tinggi memiliki prosedur yang dapat meningkatkan kualitas proses belajar mengajar dalam upaya perbaikan berkelanjutan pada perguruan tinggi.
\end{abstract}

Keywords: ISO 9001, prosedur, manajemen risiko

\section{Pendahuluan}

Dalam kancah pendidikan tinggi di Indonesia, Politeknik Negeri Batam hadir mewarnai persaingan yang ada. Politeknik Negeri Batam merupakan satusatunya perguruan tinggi negeri di Kota Batam yang sedang mengalami perkembangan yang sangat pesat. Berbagai strategi pertumbuhan dan promosi dicanangkan oleh manajemen Politeknik Negeri Batam bukan hanya sekedar memastikan keberlangsungannya di masa mendatang, namun juga meningkatkan kontribusi dan reputasinya di tingkat nasional dan internasional (Kartikasari, 2017).

Salah satu strategi Politeknik Negeri Batam untuk bertumbuh dengan pesat adalah adopsi sistem manajemen mutu ISO 9001. Di tengah persaingan pendidikan tinggi di Indonesia yang sangat ketat hingga mengancam keberlangsungan banyak perguruan tinggi (Kartikasari, 2014), Politeknik Negeri Batam menganggap bahwa manajemen mutu berbasis akreditasi saja tidaklah cukup. Faktanya, penerapan ISO 9001 di perguruan tinggi mampu meningkatkan kesempatan untuk perbaikan berkelanjutan, memudahkan proses belajar bagi karyawan baru, dan meningkatkan konsistensi dalam memberikan pelayanan terbaik (Sindhuwinata dan Felecia, 2016). Selama sebuah organisasi fokus pada manfaat ISO 9001 berupa peningkatan mutu organisasi dan bukan terjebak pada rutinitas sertifikasi yang menyebabkan sumber dayanya habis untuk sekedar mempertahankan sertifikasi, maka organisasi tersebut mestinya akan mampu meningkatkan daya saingnya secara berkelanjutan (Kartikasari dan Irawan, 2016)

\footnotetext{
*Corresponding author. E-mail: dwi@polibatam.ac.id
} 
Politeknik Negeri Batam telah memperoleh sertifikasi ISO 9001 sejak tahun 2006. Hingga saat ini yang diterapkan adalah ISO 9001:2008. Akan tetapi terjadi perkembangan terbaru di mana pada September 2015, ISO menerbitkan standar revisi terbaru sehingga standar ISO 9001:2008 sudah tidak lagi berlaku (ISO, 2015). Standar ISO 9001:2015 merupakan standar revisi terbaru yang harus diterapkan oleh sebuah organisasi. Oleh sebab itu, Politeknik Negeri Batam wajib bermigrasi atau merubah standarnya mengikuti persyaratan standar revisi terbaru yaitu ISO 9001:2015 paling lambat pada tahun 2018.

Pada ISO 9001:2015 terdapat perubahan besar utamanya mengenai penerapan risk-based thinking pada suatu organisasi di mana hal ini tidak dibahas dalam ISO 9001:2008 (Farhana et.al, 2016). Oleh sebab itu perlu dilakukan penyempurnaan pada standar operasi prosedur yang ada agar dapat memenuhi gap antara kondisi saat ini dengan requirement pada ISO 9001:2015 dengan melakukan pertimbangan risiko. Analisis pertimbangan risiko yang dilakukan dalam penelitian ini adalah penyusunan risk register dengan menggunakan risk assessment. Dokumen ini selanjutnya akan digunakan sebagai bahan pertimbangan dalam menyusun prosedur ISO sehingga pada prosedur yang baru telah mengantisipasi risiko-risiko yang muncul pada proses di organisasi tersebut.

Penelitian seperti ini telah banyak dilakukan sebelumnya, misalnya Khairunnisa et al (2016) yang membuatkan prosedur dalam rangka migrasi ISO 9001:2015 untuk sebuah perusahaan swasta. Persamaan penelitian ini dengan Khairunnisa et al (2016) adalah pendekatan studi kasusnya yang fokus hanya pada prosedur tertentu. Sedangkan perbedaannya hanya pada objek penelitian di mana pada penelitian ini objeknya adalah perguruan tinggi.

Demikian juga Wiguno (2017) yang menilai kesiapan sebuah perusahaan swasta untuk sertifikasi ISO 9001:2005 pada sebuah perusahaan swasta. Perbedaan penelitian ini dengan Wiguno (2017) adalah pendekatan Wiguno (2017) pada beberapa prosedur sekaligus terkait kepatuhan prosedur tersebut dalam memasukkan unsur manajemen risiko sehingga tidak dapat membahas rancangan perubahan prosedur yang dihasilkan.

Mattotoran dan Rahardjo (2017) membahas tentang analisis risiko di sebuah perusahaan. Penelitian ini melakukan analisis risiko pada 101 proses dan 20 prosedur pada seluruh bagian di sebuah perusahaan dengan menggunakan Failure Mode and Effect Analysis (FMEA) sehingga diperoleh 53 risiko kategori sangat tinggi di perusahaan dan cara penanganannya. Perbedaan penelitian ini dengan penelitian Mattotoran dan Rahardjo (2017) adalah fokus penelitian, di mana Mattotoran dan Rahardjo (2017) hanya fokus pada analisis risiko tanpa menjelaskan dampaknya pada perubahan prosedur yang ada.

Penelitian tentang ISO 9001 di perguruan tinggi masih relatif tidak banyak dikarenakan tingkat penetrasi penerapan ISO 9001 di perguruan tinggi masih rendah. Sistem penjaminan mutu yang wajib dilakukan oleh perguruan tinggi adalah akreditasi dari BAN PT dan SPMI, bukan dari lembaga lain seperti ISO. Karena itu tidak banyak perguruan tinggi yang melakukan sertifikasi ISO 9001 (Antariksa, Surachman, \& Setiawan, 2014). Oleh sebab itu, artikel ini bermanfaat untuk memperkaya literatur di bidang penerapan ISO pada pendidikan tinggi.

\section{Tinjauan Literatur}

Penelitian ini dijalankan berdasarkan kerangka pemikiran sebagai berikut:

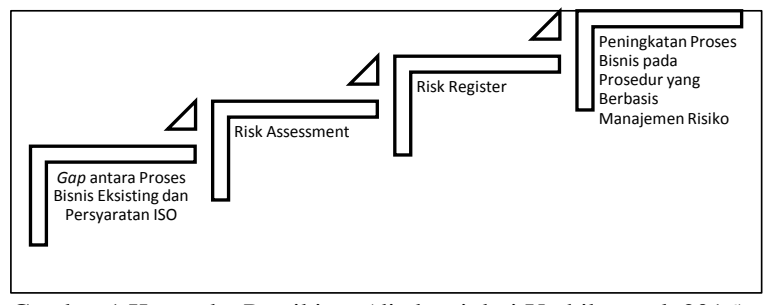

Gambar 1 Kerangka Pemikiran (diadopsi dari Yuthika et al, 2016)

Gambar di atas menjelaskan bahwa adanya gap atau perbedaan antara proses bisnis eksisting dengan requirement ISO adalah dasar bagi risk assessment yang dilanjutkan dengan risk register. Kedua proses ini adalah proses dasar dalam manajemen risiko. Selanjutnya manajemen risiko yang diperoleh akan diintegrasikan dengan proses bisnis eksisting perusahaan sehingga menghasilkan rancangan prosedur yang efektif dan efisien bagi organisasi.

\section{Metode Penelitian}

Obyek penelitian adalah Jurusan Manajemen Bisnis Politeknik Negeri Batam. Jurusan bertanggung jawab atas empat buah SOP yang mencakup SOP pengembangan kurikulum, SOP pengembangan bahan ajar, SOP pelaksanaan pembelajaran, dan SOP penilaian dan evaluasi pembelajaran. Untuk artikel ini, 
karena keterbatasan jumlah halaman yang diperbolehkan dan kerahasiaan data yang dapat ditampilkan, maka penulis melakukan studi kasus pada prosedur PR.8.1-V5 Perencanaan Proses Belajar Mengajar (PBM). Data primer dikumpulkan melalui focus group discussion dengan pejabat struktural di jurusan manajemen bisnis. Sedangkan data sekunder diperoleh dari pusat penjaminan mutu Politeknik Negeri Batam, dan sumber-sumber daring lain yang valid.

Metode analisis manajemen risiko dilakukan dengan memasukkan risiko yang teridentifikasi ke dalam risk management form. Dengan metode ini, risiko kegagalan dan efeknya ditentukan oleh dua faktor, yaitu 1) probabilitas dan frekuensi terjadinya kegagalan, serta 2) besarnya dampak yang terjadi apabila kegagalan terjadi. Untuk setiap risiko yang teridentifikasi, risiko tersebut akan digolongkan tingkat keparahannya ke dalam 5 tingkatan, yaitu:

1. Tidak signifikan (akibat hanya di area tersebut)

2. Kecil (dampaknya sampai satu bagian/departemen)

3. Sedang (akibatnya sampai satu institusi)

4. Besar (akibatnya sampai ke pelanggan, atau jumlah kerugian mencapai lebih dari 20 juta rupiah)

5. Bencana (dampaknya sampai ke pemerintah atau masyarakat luas)

Sedangkan probabilitas dan frekuensi terjadinya kegagalan juga digolongkan menjadi 5 tingkat, yaitu:

1. Sangat jarang (hampir tidak pernah terjadi dalam kurun waktu 1-5 tahun)

2. Jarang (dalam setahun tidak ada)

3. Mungkin (dalam setahun ada 1- 5 kali)

4. Mungkin sekali (lebih dari 1 kali tiap bulan)

5. Hampir pasti (beberapa kali tiap peristiwa/tiap hari terjadi)

Setelah penggolongan di atas dilaksanakan, dilakukan perhitungan pembobotan terhadap semua risiko yang teridentifikasi (risk assessment). Perhitungan pembobotan risiko dilakukan dengan rumus sebagai berikut:

\section{Bobot risiko $=$ probabilitas $\mathrm{x}$ dampak}

Hasil dari penilaian/pembobotan risiko berada pada kisaran angka 1 hingga 25 . Selain itu, risiko juga digolongkan menjadi 4 tingkatan sesuai dengan kriteria di bawah ini:

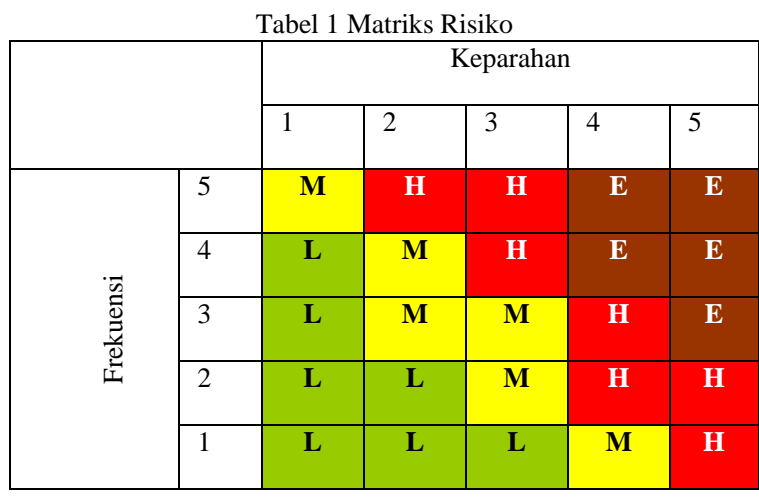

Adapun keempat tingkatan risiko sesuai dengan tabel di atas adalah:

1. Low atau tingkat risiko rendah

2. Medium atau tingkat risiko menengah

3. High atau tingkat risiko tinggi

4. Extreme atau tingkat risiko sangat tinggi

Risiko yang teridentifikasi beserta bobotnya akan dimasukkan ke dalam risk register sesuai prioritas, yaitu risiko dengan bobot tertinggi akan ditempatkan di paling atas. Risk register ini dibuat untuk memastikan bahwa risiko dengan bobot tertinggi memperoleh perhatian utama untuk penanganannya yang meliputi pencegahan ataupun pengurangan potensi keterjadiannya maupun dampaknya. Penulis selanjutnya harus terus-menerus memperhatikan bahwa semua risiko, utamanya risiko dengan tingkatan extreme, dipertimbangkan dalam perancangan SOP yang berbasis manajemen risiko.

\section{Hasil dan Pembahasan}

Setiap proses mulai dari perencanaan, pelaksanaan, hingga evaluasi kegiatan belajar mengajar memiliki kemungkinan-kemungkinan risiko yang potensial terjadi. Untuk mengatasi segala risiko yang mengancam maka perlu dilakukan identifikasi risiko di setiap proses. Penilaian ini berdasarkan diskusi dengan penanggung jawab SOP. Penilaian risiko kegiatan belajar mengajar, khususnya untuk prosedur PBM PR.8.1-V5 Perencanaan Proses Belajar Mengajar dapat dilihat pada Tabel 2.

Tabel 2 disusun berdasarkan risiko yang teridentifikasi pada saat diskusi dengan penanggung jawab prosedur. Oleh sebab itu, urutannya tidak berdasarkan nilai/bobot risiko yang disepakati. Semua risiko yang berkaitan dengan perencanaan PBM disampaikan serta langsung diidentifikasi dampak dan 
pencegahannya pada prosedur yang telah ada saat ini yaitu prosedur yang berbasis ISO 9001:2008. Dari tabel di atas, penulis dapat mengumpulkannya ke dalam daftar risiko (risk register) sesuai urutan prioritas, bersama dengan action plan dan penanggung jawab per aktivitas.

Tabel 2 Penilaian Risiko (Risk Assessment)

\begin{tabular}{|c|c|c|c|c|c|c|c|c|}
\hline Kode & Risk/Issue & Dampak & $\begin{array}{l}\text { Pihak } \\
\text { terkait }\end{array}$ & Kontrol / Pencegahan Saat ini / Gap & $\begin{array}{c}\text { Dam- } \\
\text { pak }\end{array}$ & $\begin{array}{l}\text { Frek- } \\
\text { uensi }\end{array}$ & $\begin{array}{l}\text { Nilai / } \\
\text { Bobot } \\
\text { Risiko }\end{array}$ & $\begin{array}{l}\text { Tingkat } \\
\text { Risiko }\end{array}$ \\
\hline 1 & Referensi out of date & $\begin{array}{l}\text { Tidak } \\
\text { mengetahui } \\
\text { perkembangan } \\
\text { terkini }\end{array}$ & $\begin{array}{l}\text { Mahasiswa } \\
\text { dan dosen }\end{array}$ & Tidak ada batasan maksimal tahun referensi & 2 & 3 & 6 & $\mathrm{M}$ \\
\hline 2 & $\begin{array}{l}\text { Referensi susah didapat, } \\
\text { tidak tersedia di toko } \\
\text { buku }\end{array}$ & $\begin{array}{l}\text { Mahasiswa } \\
\text { tidak membaca } \\
\text { buku }\end{array}$ & $\begin{array}{l}\text { Mahasiswa } \\
\text { dan dosen }\end{array}$ & $\begin{array}{l}\text { Dosen dapat mengajukan, tapi biasanya setahun } \\
\text { sekali. Sebaiknya dibuat lebih kerap pada saat } \\
\text { evaluasi SAP/GBPP/RPS (Satuan Acara } \\
\text { Perkuliahan/Garis-Garis Besar Program } \\
\text { Perkuliahan/Rencana Pembelajaran Semester) }\end{array}$ & 4 & 3 & 12 & $\mathrm{H}$ \\
\hline 3 & $\begin{array}{l}\text { Jumlah buku referensi di } \\
\text { perpustakaan kurang } \\
\text { banyak }\end{array}$ & $\begin{array}{l}\text { Mahasiswa } \\
\text { tidak membaca } \\
\text { buku }\end{array}$ & $\begin{array}{l}\text { Mahasiswa } \\
\text { dan dosen }\end{array}$ & agar dosen tidak lupa mengajukan. & & & & \\
\hline 4 & $\begin{array}{l}\text { Ketersediaan materi di } \\
\text { e-learning dan server }\end{array}$ & $\begin{array}{l}\text { Dosen pengajar } \\
\text { sulit } \\
\text { mempersiapkan } \\
\text { diri }\end{array}$ & Jurusan & $\begin{array}{l}\text { Biasanya jurusan mengingatkan dosen paling } \\
\text { lambat sehari sebelum perkuliahan harus sudah } \\
\text { diupload. Sebaiknya langsung di-upload setelah } \\
\text { rapat SAP/GBPP/RPS }\end{array}$ & 3 & 4 & 12 & $\mathrm{H}$ \\
\hline 5 & $\begin{array}{l}\text { Peran cluster (Kelompok } \\
\text { Keahlian Terapan/KKT) } \\
\text { kurang optimal } \\
\text { mendukung kegiatan } \\
\text { pengajaran dan atau } \\
\text { penelitian dosen }\end{array}$ & $\begin{array}{l}\text { Dosen kesulitan } \\
\text { untuk fokus } \\
\text { pada cluster } \\
\text { tertentu }\end{array}$ & Jurusan & $\begin{array}{l}\text { Saat ini rapat SAP/GBPP/RPS diadakan dengan } \\
\text { semua dosen. Akan lebih baik apabila sebelum } \\
\text { rapat, dosen-dosen dalam satu KKT/cluster telah } \\
\text { melaksanakan rapat pendahuluan. }\end{array}$ & 3 & 3 & 9 & $\mathrm{M}$ \\
\hline
\end{tabular}

Dari Tabel 3 terlihat bahwa untuk prosedur perencanaan PBM, risiko terkait referensi yang digunakan serta ketersediaan materi di learning menjadi pusat perhatian jurusan. Oleh sebab itu, penulis merancang prosedur baru untuk mengintegrasikan semua risiko yang teridentifikasi di atas. Adapun prosedur perencanaan PBM yang dirancang berdasarkan analisis risiko terlihat pada Gambar 2.

Tabel 3. Daftar Risiko dan Rencana Aksinya

\begin{tabular}{|c|c|c|c|c|c|c|}
\hline No & Kode & Risk/Issue & $\begin{array}{l}\text { Nilai / } \\
\text { Bobot } \\
\text { Risiko }\end{array}$ & $\begin{array}{l}\text { Tingkat } \\
\text { Risiko }\end{array}$ & Rencana Aksi & PIC \\
\hline 1 & 2 & $\begin{array}{l}\text { Referensi susah didapat, tidak } \\
\text { tersedia di toko buku }\end{array}$ & \multirow[t]{2}{*}{12} & \multirow[t]{2}{*}{$\mathrm{H}$} & $\begin{array}{l}\text { 1. Memasukkan borang perpustakaan No.BO.31.1.1.V4 Usulan } \\
\text { Penambahan Koleksi Perpustakaan ke dalam prosedur } \\
\text { perencanaan PBM } \\
\text { 2. Memasukkan saran penggunaan e-book dalam referensi } \\
\text { SAP/GBPP/RPS (langsung dimasukkan ke dalam catatan }\end{array}$ & \multirow[t]{2}{*}{$\begin{array}{l}\text { Dosen } \\
\text { pengampu/ } \\
\text { dosen } \\
\text { koordinator }\end{array}$} \\
\hline 2 & 3 & $\begin{array}{l}\text { Jumlah buku referensi di } \\
\text { perpustakaan kurang banyak }\end{array}$ & & & $\begin{array}{l}\text { formulir) } \\
\text { 3. Mengusulkan kepada bagian perpustakaan untuk pengelolaan e- } \\
\text { book } \\
\text { 4. Mengusulkan kepada koperasi untuk menjual buku-buku kuliah }\end{array}$ & \\
\hline \multirow[t]{2}{*}{3} & \multirow[t]{2}{*}{4} & $\begin{array}{l}\text { Ketersediaan materi di e- } \\
\text { learning dan server }\end{array}$ & \multirow[t]{2}{*}{12} & \multirow[t]{2}{*}{$\mathrm{H}$} & $\begin{array}{l}\text { Memasukkan aktivitas unggah materi di e-learning dan server segera } \\
\text { setelah rapat SAP/GBPP/RPS selesai pada prosedur perencanaan } \\
\text { PBM }\end{array}$ & $\begin{array}{l}\text { Dosen } \\
\text { pengampu/ } \\
\text { dosen } \\
\text { koordinator }\end{array}$ \\
\hline & & & & & $\begin{array}{l}\text { Memasukkan aktivitas pengecekan materi learning oleh KPS sehari } \\
\text { sebelum perkuliahan dimulai dan mengirimkan email peringatan } \\
\text { untuk yang belum mengunggah pada prosedur perencanaan PBM }\end{array}$ & KPS \\
\hline 4 & 5 & $\begin{array}{l}\text { Peran } \text { cluster (KKT) kurang } \\
\text { optimal mendukung kegiatan } \\
\text { pengajaran dan atau } \\
\text { penelitian dosen }\end{array}$ & 9 & $\mathrm{M}$ & $\begin{array}{l}\text { Memasukkan rapat KKT (cluster) sebelum rapat SAP/GBPP/RPS } \\
\text { pada prosedur perencanaan PBM, sehingga KKT bukan hanya fokus } \\
\text { pada penelitian, namun juga bidang pengajaran. }\end{array}$ & Ketua KKT \\
\hline
\end{tabular}




\begin{tabular}{|c|c|c|c|c|c|c|}
\hline & Kode & Risk / Issue & $\begin{array}{l}\text { Nilai / } \\
\text { Bobot } \\
\text { Risiko }\end{array}$ & $\begin{array}{l}\text { Tingkat } \\
\text { Risiko }\end{array}$ & Rencana Aksi & PIC \\
\hline 5 & 1 & Referensi out of date & 6 & $\mathrm{M}$ & $\begin{array}{l}\text { Memasukkan batasan maksimal tahun referensi pada } \\
\text { SAP/GBPP/RPS khususnya untuk sumber primer berupa jurnal } \\
\text { (langsung dimasukkan ke dalam catatan formulir saja tanpa merubah } \\
\text { prosedur). }\end{array}$ & $\begin{array}{l}\text { Dosen } \\
\text { pengampu/ } \\
\text { dosen } \\
\text { koordinator }\end{array}$ \\
\hline
\end{tabular}

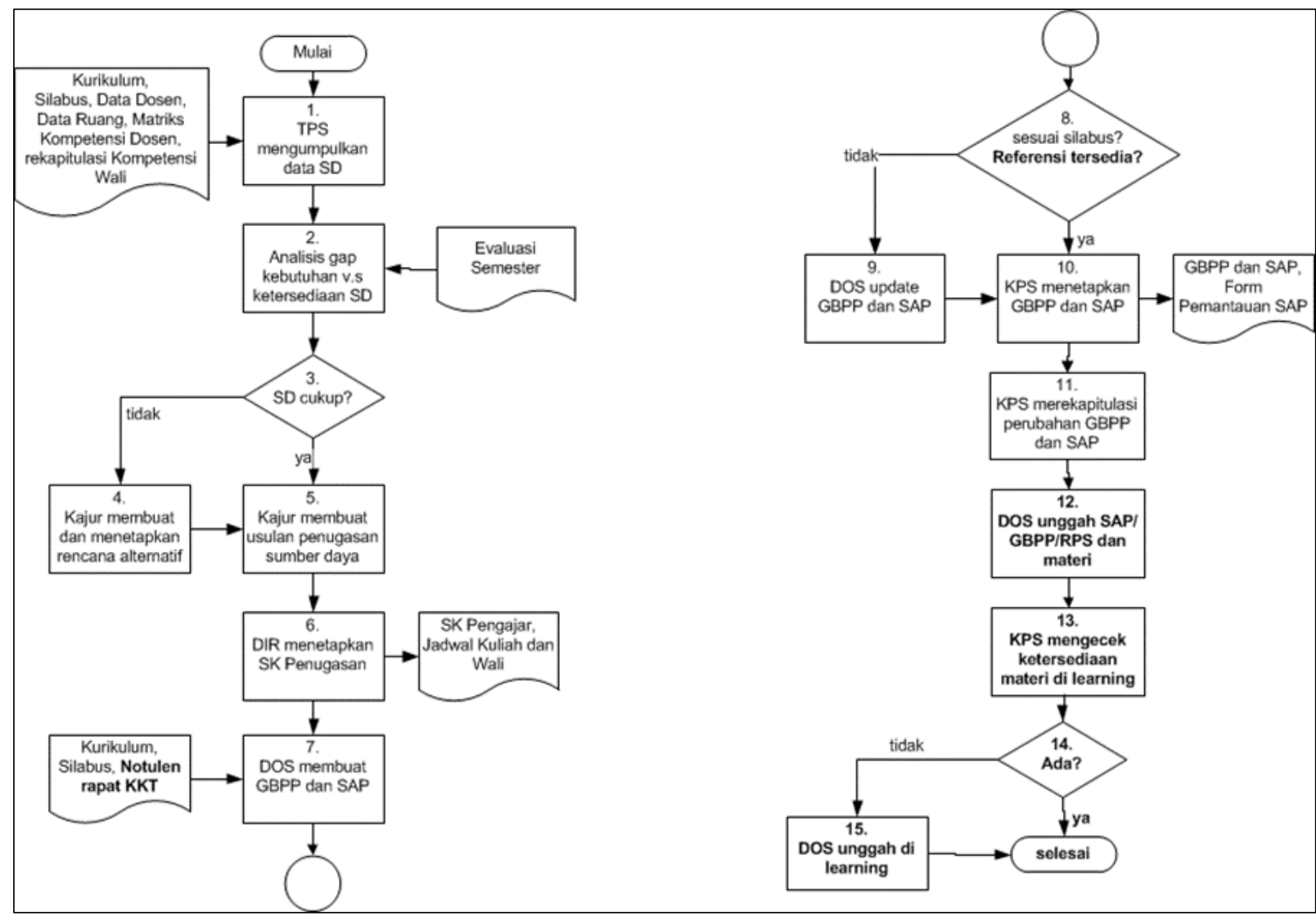

Gambar 2 Rancangan Prosedur Berbasis Manajemen Risiko

Pada Gambar 2 rancangan prosedur berbasis manajemen risiko, penulis memberikan tanda huruf tebal (bold) pada setiap aktivitas yang diubah untuk mengintegrasikan risiko yang telah diidentifikasi sebelumnya. Adapun uraian kegiatan perencanaan PBM dapat dijelaskan sebagai berikut:

1. Tata Usaha mengumpulkan data sumber daya. Penanggung jawabnya adalah Tata Usaha. Masukannya adalah Kurikulum, silabus, BO.8.1.1, BO.8.1.2, BO.8.1.3, BO.8.1.4, BO.8.1.5.

2. Ketua Jurusan melakukan analisis gap kebutuhan dengan ketersediaan SD yang ada pada bulan JuniJuli. Penanggung jawabnya adalah Kajur. Masukannya adalah FO. 9.1.2.
3. Jika sumber daya tidak cukup lanjut ke langkah 4 . Jika cukup lanjut ke langkah 5. Penanggung jawabnya adalah Kajur.

4. Jika sumber daya tidak cukup maka Kajur membuat dan menetapkan rencana alternatif, alternatif strategi pemenuhan yang dapat dilakukan dapat berupa:

a. Perekrutan internal/eksternal.

b. Outsourcing.

c. Pembinaan, pelatihan, dsb.

d. Penyesuaian kapasitas kelas.

e. atau strategi lain yang layak.

Sedangkan untuk sumber daya non manusia, alternatif strategi pemenuhan dapat berupa: 

a. Pengadaan.
b. Penjadwalan.

Untuk mata kuliah umum (MKU), pelaksanaan proses ini melibatkan ketua MKU. Penanggung jawabnya adalah Kajur dan Ka. MKU. Jika sumber daya cukup maka Kajur membuat usulan penugasan sumber daya. Penanggung jawabnya adalah Kajur. Inputnya adalah BO.8.1.6.

5. Direktur menetapkan surat keputusan penugasan mengajar untuk dosen (DOS). Keluarannya adalah SK mengajar, SK wali, dan jadwal kuliah.

6. DOS membuat GBPP/SAP/RPS. GBPP/SAP/RPS dibuat berdasarkan silabus dan masukan dari rekan-rekan dosen dalam satu KKT. Pembuatan SAP/GBPP/RPS juga dapat menggunakan hasil masukan pelaksanaan mata kuliah pada semester sebelumnya. Penanggung jawabnya adalah DOS. Inputnya adalah kurikulum, silabus, dan notulen rapat.

7. Jika SAP/GBPP/RPS tidak sesuai silabus dan referensi tersedia maka lanjut ke langkah 9. Jika sesuai lanjut ke langkah 10. Penanggung jawabnya adalah KPS.

8. Apabila SAP/GBPP/RPS tidak sesuai silabus atau referensi tidak tersedia, DOS harus meng-update sesuai hasil rapat pada langkah 9. Perbaikan diverifikasi oleh Ketua Program Studi (KPS). Jika referensi tidak tersedia, DOS harus mengisi borang BO.31.1.1.V4 Usulan Penambahan Koleksi Perpustakaan.

9. Apabila SAP/GBPP/RPS sesuai dengan silabus dan referensi tersedia atau borang usulan penambahan koleksi perpustakaan telah diisi, KPS menetapkan SAP/GBPP/RPS tersebut serta membuatkan jadwal perkualiahan yang akan dipergunakan pada semester berikutnya. Rapat SAP/GBPP/RPS dilaksanakan paling lambat 1 minggu sebelum pelaksanaan PBM dimulai. Penanggung jawabnya adalah KPS. Keluarannya adalah FO.8.1.1, FO.8.1.2, BO.8.2.1.

10. Melakukan rekapitulasi perubahan GBPP dan SAP, dan kemudian menyerahkan hasil rekapitulasi ke Keuangan. Rekapitulasi hanya untuk GBPP dan SAP yang mengalami perubahan substantif. Penanggung jawabnya adalah KPS. Keluarannya adalah BO.8.1.7.

11. DOS mengunggah SAP/GBPP/RPS dan materi kuliah di learning.

12. KPS mengecek ketersediaan SAP/GBPP/RPS dan materi kuliah di learning.

13. Jika SAP/GBPP/RPS dan materi tersedia di learning maka selesai. Jika tidak tersedia, maka lanjut ke langkah 15. Penanggung jawabnya adalah KPS.

14.DOS mengunggah SAP/GBPP/RPS dan materi kuliah di learning.

Perubahan uraian prosedur dilaksanakan mulai aktivitas ketujuh, yaitu mengenai pembuatan SAP/GBPP/RPS. Perubahan prosedur dilaksanakan untuk meningkatkan kualitas perencanaan proses belajar mengajar. Semua dokumen yang terlibat dalam prosedur ini disimpan di Tata Usaha dengan masa penyimpanan 5 tahun. Adapun daftar dokumen yang terlibat dalam prosedur ini adalah:

a. No.BO.8.1.1-V1 Borang PBM - Inventarisasi Kurikulum dan Sumber Daya Pendukungnya.

b. No.BO.8.1.2-V1 Borang PBM - Matriks Kompetensi Dosen.

c. No.BO.8.1.3-V1 Borang PBM - Rekapitulasi Kompetensi Wali Akademik.

d. No.BO.8.1.4-V0 Borang PBM - Identifikasi kompetensi Dosen.

e. No.BO.8.1.5-V0 Borang PBM - Evaluasi Kompetensi Wali Akademik.

f. No.BO.8.1.6-V0 Borang PBM - Distribusi Beban Mengajar.

g. No.BO.8.1.7-V0 Borang PBM - Rekapitulasi Perubahan GBPP/SAP .

h. No.FO.8.1.1-V0 Format PBM - GBPP.

i. No.FO.8.1.2-V0 Format PBM - SAP.

j. No.FO.6.1.2-V0 Format RPS.

k. BO.31.1.1.V4 Usulan Penambahan Koleksi Perpustakaan.

Rancangan prosedur perencanaan PBM ini telah memenuhi requirement berdasarkan standar ISO 9001:2015 karena telah memasukkan risiko-risiko yang teridentifikasi. Prosedur ini lebih efektif dibanding prosedur yang saat ini ada karena lebih terintegrasi dengan bagian lain sehingga meminimalisasi borang lambat terisi. Rancangan prosedur dapat dilaporkan kepada bagian penjaminan mutu untuk dievaluasi kemungkinan implementasinya dalam upaya perbaikan berkelanjutan pada organisasi.

\section{Penutup}

Berdasarkan penelitian yang telah dilakukan diketahui bahwa persyaratan migrasi ke ISO 9001:2015 adalah prosedur yang memasukkan unsur manajemen risiko ke dalamnya. Dalam penelitian ini, diperoleh apa saja risiko-risiko yang teridentifikasi 
dalam kegiatan perencanaan proses belajar mengajar, apa saja dan seberapa parah dampaknya, seberapa mungkin tingkat probabilitas/frekuensi keterjadiannya, sehingga dapat dihitung nilai/bobot risiko tersebut. Pada penelitian ini juga diperoleh daftar risiko beserta rencana aksinya. Daftar risiko diurutkan berdasarkan nilai/bobot risiko terbesar dengan harapan risiko terbesar akan memperoleh perhatian utama. Pada penelitian ini, untuk prosedur perencanaan PBM, risiko terbesar adalah ketersediaan referensi dan ketersedian SAP/GBPP/RPS dan materi di learning. Berdasarkan informasi daftar risiko ini, dirancanglah prosedur perencanaan PBM yang baru yang mampu mengantisipasi/mencegah terjadinya risiko yang tercantum dalam daftar risiko. Hasil rancangan prosedur perencanaan PBM yang baru diharapkan lebih efektif dan dapat diimplementasikan untuk mendukung perbaikan berkelanjutan di perguruan tinggi ini.

\section{Ucapan Terima Kasih}

Ucapan terima kasih kepada pejabat struktural jurusan Manajemen Bisnis yaitu Mega Mayasari, Nanik Lestari, Rahmat Hidayat, dan Seto Sulaksono, serta bagian Penjaminan Mutu yaitu Siti Aisyah dan Rahmatullaili atas kontribusinya sebagai narasumber dalam artikel ini.

\section{References}

Antariksa, W. F., Surachman, \& Setiawan, M. (2014). Pengaruh Penerapan Sistem Manajemen Mutu ISO 9001:2008 di Perguruan Tinggi terhadap Kinerja Balanced Scorecard (Studi Kasus pada Universitas Brawijaya). Jurnal Aplikasi Manajemen, 12(3), pp. 399-406.

Farhana, N., Widaningrum, S., dan Lalu, H., (2016). Perancangan SOP Management Review Berdasarkan Integrasi ISO 9001:2015 (Klausul 9.3) Dan ISO 14001:2015 (Klausul 9.3) Dengan Mempertimbangkan Risiko Menggunakan Metode Benchmark Di CV XYZ. Jurnal Rekayasa Sistem \& Industri 3(3), pp. 39-47.

ISO. (2015). ISO 9001:2015 Quality Management System Requirement. Swiss: ISO

Kartikasari, D., (2017). Market Segmentation of Industry-Education Partnership Classes (Case Study: Batam State Polytechnic). The 3rd International Conference on Education \& Training (ICET), Universitas Malang, 30 September - 01 Oktober 2017.

Kartikasari, D., (2014). Analisis Persaingan Pendidikan Tinggi Di Batam dari Perspektif Politeknik Batam. Cakrawala
Pendidikan, 33(2), pp. 211-224. Available at http://dx.doi.org/10.21831/cp.v2i2.2148.

Kartikasari, D. and Irawan, A., (2016). Do ISO 900x Series Really Make A Difference In Financial Performance? A Case Study Of Manufacturing Companies Listed In The Indonesia Stock Exchange. The 13th Universiti Malaysia Terengganu International Annual Symposium on Sustainability Science and Management (UMTAS 2016). pp. 635-641. 13-15 Desember 2016.

Khairunnisa, S., Widaningrum, S., dan Lalu, H. (2016) Perancangan SOP Audit Internal Berdasarkan Integrasi ISO 9001:2015 (Klausul 9.2) dan ISO 14001:2015 (Klausul 9.2) dengan Mempertimbangkan Risiko Menggunakan Metode Benchmark di CV XYZ. Jurnal Rekayasa Sistem \& Industri. 3(2), pp. 38-46

Mattotoran, A. dan Rahardjo, J. (2017). Perancangan Analisa Risiko pada Sistem ISO 9001:2015 di PT. X. Jurnal Titra, 5(2), pp. 181-188.

Sindhuwinata, O., E., and Felecia, (2016). Perancangan Sistem Manajemen Mutu ISO 9001:2015: Studi Kasus. Jurnal Titra, 4(2), pp. 183-190.

Yuthika, R., Widaningrum, S., dan Lalu, H. (2016). Perancangan SOP Pengendalian Informasi Terdokumentasi Berdasarkan Integrasi ISO 9001:2015 Klausul 7.5 Dan ISO 14001:2015 Klausul 7.5 Dengan Mempertimbangkan Risiko Menggunakan Metode Business Process Improvement Di CV. XYZ. e-Proceeding of Engineering. 3(2). pp. 2815-2821.

Wiguna, R., B. (2017). Perancangan Sistem Manajemen Mutu ISO 9001:2015 Di Departemen Printing Development PT. X. Jurnal Titra, 5(2), pp. 371-378. 